\title{
LIÇÕES DO TRABALHO ASSOCIADO: EDUCAÇÃO, EXPERIÊNCIA E MEMÓRIA COLETIVA
}

\author{
Lia Tiriba ${ }^{1}$ \\ Lívia Diana Rocha Magalhães ${ }^{2}$
}

\section{RESUMO}

Concentramo-nos na análise do trabalho associado, tomando como referência as contribuições de Edward Palmer Thompson sobre história e experiência de classe, bem como o conceito de memória coletiva de Maurice Halbwachs. Confrontando com as formas capitalistas de organização do trabalho, analisamos as dimensões técnico-produtivo e éticopolíticas das relações entre trabalho e educação em experiências vividas por trabalhadores fabris durante a Guerra Civil Espanhola (1936-1939) e no Processo Revolucionário em Curso - PREC (Portugal, 1974-1975). Revisitamos essas experiências coletivas, considerando a memória transmitida e transformada no processo de instauração e de consolidação desses espaços/tempos históricos do trabalho de produzir a vida associativamente.

Palavras-chave: Trabalho e Educação; Trabalho associado; Memória; História.

\section{ABSTRACT}

We focus on the analysis of the associated work, taking as reference the contributions of Edward Palmer Thompson on history and class experience, as well as the concept of collective memory by Maurice Halbwachs. Confronting the capitalist forms of work organization, we analyze the technical-productive and ethical-political dimensions of the relations between work and education in experiences lived by factory workers during the Spanish Civil War (1936-1939) and in the Revolutionary Process in Progress - PREC (Portugal, 1974-1975). We revisit these collective experiences, considering the memory transmitted and transformed in the process of instituting and consolidating these historical spaces / times of the work of producing life associatively

Keywords: Work and education; Associated work; Memory; History. 


\section{Introdução}

Nosso propósito é recompor lições históricas de experiências de trabalho associado, entendidas como experiências de classe, nas quais homens e mulheres tentam reorganizar, inventar e recriar o processo de trabalho, de maneira a rearticular os saberes fragmentados e historicamente negados à classe trabalhadora. Afirmar que os diversos momentos históricos em que trabalhadores e trabalhadoras experienciaram a ocupação e a apropriação coletiva dos meios de produção da vida social constituem-se como espaços/tempos de mobilização, sistematização e produção de saberes, os quais podemos denominar de saberes do trabalho associado (FISCHER; TIRIBA, 2009).

Assim como toda categoria histórica, a categoria produção associada/trabalho associado só tem validade se forem consideradas as mediações que tecem sua materialidade histórica. Nessa perspectiva, focalizamos aspectos da organização do trabalho em espaços/tempos do trabalho de produzir a vida associativamente, de cunho revolucionário. Partimos do pressuposto de que, quando está em jogo a hegemonia do trabalho sobre o capital, um grupo de trabalhadores/as associados/as ou comunidades inteiras persistiram em criar, recriar e afirmar culturas do trabalho que contrariam a perspectiva de mercantilização da força de trabalho e da própria vida.

Partindo da premissa marxiana do trabalho como princípio educativo e das contribuições teórico-metodológicas de Edward Palmer Thompson sobre história e experiência de classe e de Maurice Halbwachs sobre memória coletiva, concentramos a atenção no caráter técnico-produtivo e ético-político da organização do trabalho em experiências vividas por trabalhadores fabris durante a Guerra Civil Espanhola (1936-1939) e no Processo Revolucionário em Curso (PREC), ocorrido em Portugal (1974-1975). Para discutir esses processos e experiências educativas, tomamos as contribuições de Thompson (2001) e Halbwachs (2003), uma vez que resguardadas suas diferenças teóricas políticas quanto aos fundamentos teórico-metodológicos de análise da realidade humano-social, ambos nos conduzem a discutir as experiências coletivas, bem como a memória que permanece presente como mediação entre experiências vividas e experiências modificadas.

Recorremos particularmente a Thompson (2001) quando afirma que em suas análises históricas, sociológicas e políticas, o pesquisador deve lembrar que "os fenômenos sociais e culturais não correm atrás do econômico após longa demora; estão na sua origem, imersos no mesmo nexo relacional" (2001, p. 267). Sendo a classe um fenômeno econômico e cultural,

[...] a classe se delineia segundo o modo como homens e mulheres vivem suas relações de produção e segundo a experiência de suas situações determinadas, no interior do 'conjunto de suas relações sociais', com a cultura e as expectativas a eles transmitidas e com base no modo pelo qual se valeram dessas experiências em nível cultural (THOMPSON, 2001, p. 277, grifo do autor).

Para esse autor, por ser uma formação tanto cultural como econômica, a classe é uma relação social, é fruto de experiências comuns, vividas, herdadas e partilhadas, que são em grande medida, mas não apenas, determinadas pelas relações de produção. A análise do processo histórico pressupõe o entendimento de como, pela experiência, homens e mulheres vivem, percebem, sentem, fazem e refazem o conjunto das relações sociais, determinadas tanto por pressões externas como pela vontade coletiva.

Ao considerar as múltiplas determinações que conformam os movimentos do real, para Thompson (1981) a História deve ser entendida como um processo estruturado, 
que tem por base (infraestrutura) as relações sociais de produção, que são hegemônicas em determinados espaços/tempos históricos. Mesmo se colocando contrário ao perigo do "reducionismo econômico" e/ou explicações simplistas e dogmáticas sobre o processo histórico, Thompson não desconhece e não desconsidera as determinações econômicas que tornam um dado modo de produção hegemônico. Na verdade, o método da lógica histórica convida-nos a perceber que, no processo histórico, entram em cena outras determinações, em especial as da agência humana.

É pela capacidade de ação/pensamento/ação, é pela práxis e pela própria agência humana que se dá a possibilidade de criação e recriação da realidade humano-social. Daí a necessidade do exercício de captar a "história vista de baixo" ou "pelos de baixo", o que requer a valorização de experiências passadas e presentes da classe trabalhadora, tecidas nas condições objetivas e subjetivas do contexto real, do qual as experiências emergem. Em defesa do materialismo histórico, Thompson (1981, p. 15) reivindica a experiência como "uma categoria que, por mais imperfeita que seja, é indispensável ao historiador". Pensamento, sentimento e ação caminham juntos, assim a experiência não é meramente prática:

[...] pela experiência os homens [e mulheres] se tornam sujeitos, experimentam situações e relações produtivas como necessidades e interesses, como antagonismos. Eles [e elas] tratam essa experiência em sua consciência e sua cultura e não apenas a introjetam. Ela não tem um caráter só cumulativo. Ela é fundamentalmente qualitativa (THOMPSON, 1981, p. 99).

Para Thompson (1981, p. 57), "a história não conhece verbos regulares" e "se a experiência aparece como determinada, o mesmo não acontece com a consciência de classe" (THOMPSON, 1987, p. 10). Ao fazer generalizações apressadas e ocultar os conflitos sociais, a "história vista de cima" pode reduzir a História à história dos dominadores, por isso ganha relevância a análise da ação humana, ou seja, o papel ativo dos homens e mulheres no processo de produção da vida social. Este é o propósito de revisitar experiências de trabalho associado.

Por outro lado, apoiamo-nos em Maurice Halbwachs (2003). Embora não ressalve que há conflitos e contradições da sociedade de classe que compõem a memória coletiva, o autor contribui significativamente para a compreensão de que "não existe memória possível fora dos quadros sociais dos quais os homens que vivem em sociedade se servem para fixar e reencontrar as suas recordações" (HALBWACHS, 2003, p. 79). É também nos grupos sociais, dos quais os indivíduos fazem parte, que ocorrem a construção de memórias coletivas de experiências vividas ou recebidas, que por sua vez se tornam elo de identificação com esses grupos, pelo menos enquanto à eles, essas lhe forem necessárias para interpretar, refutar ou reconstruir dada realidade. Todavia, para que essas experiências vividas ou herdadas sejam percebidas e entendidas como parte integrante da realidade histórica, é preciso que ganhem o círculo das preocupações coletivas (MAGALHÃES, 2007).

De cunho histórico-documental, nossa pesquisa sobre trabalho associado tem como base os regulamentos de comissões de fábrica, jornais e outros registros sobre os saberes necessários para garantir os rumos da produção durante os períodos mencionados. Como afirma Saviani (2004), as fontes servem como testemunhos dos atos históricos dos seres humanos, constituindo-se como fonte do conhecimento histórico. Também consideramos que elas são aparatos capazes de revelar experiências e memórias individuais e coletivas daquilo que é vivido diretamente no cotidiano dos espaços e tempos concretos, considerados 
em sua totalidade. Como veremos, a análise do estudo em questão nos reafirma que, como elementos constitutivos do "fazer-se" da classe trabalhadora (THOMPSON, 1987), as lutas sociais e políticas e os processos educativos vividos e percebidos no chão de fábrica vão tecendo uma memória coletiva do trabalho de produzir a vida associativamente, mediadas por experiências anteriormente vividas ou herdadas.

No primeiro momento deste texto, pontuamos fases do desenvolvimento das forças produtivas do capital, indicando não se tratar apenas de desenvolvimento da "base técnica da produção", mas também de refinamento dos princípios ético-políticos, que, historicamente destituem a classe trabalhadora do controle do processo de trabalho. Como contraposição à produção capitalista, apresentamos a produção associada. Em seguida, recuperamos dados empíricos sobre as relações entre trabalho e educação em experiências de trabalho associado durante a Guerra Civil Espanhola (1936-1939) e o Processo Revolucionário em Curso - PREC (Portugal, 1974-1975), ressaltando a relação dialética e, portanto contraditória das dimensões técnico-produtivo e ético-político da organização do trabalho e dos processos de formação de trabalhadores/as. No terceiro e último momento, enfatizamos a importância do registro e análise de experiências de trabalho associado, na perspectiva de torná-las parte constituinte da história e memória do trabalho, em especial da memória da classe trabalhadora. Como Lavabre (2003, p. 11), entendemos que as "interações dinâmicas entre passado e presente, entre indivíduos e grupos, entre experiências vividas ou transmitidas" passam a ser compartilhadas coletivamente, contribuindo para que homens e mulheres, como forma de disputa e resistência política à exploração do trabalho, confrontem a produção capitalista com a produção associada.

\section{Produção capitalista e produção associada: dimensões técnico-produtivas e ético- políticas da organização do trabalho}

O que nos permite afirmar o princípio educativo do trabalho é a compreensão da centralidade do trabalho na formação humana é o entendimento de que só é possível existir vida humana na face da Terra se os seres humanos, mediados pelo trabalho, transformam a si mesmos e a natureza em seu entorno, criando e recriando a realidade humano-social. No encontro com a natureza, percebemos e apreendemos seus fenômenos, produzimos cultura e nos produzimos como seres de cultura, modificando-nos como elementos da natureza; na relação com outros grupos e classes sociais, produzimos maneiras de fazer, pensar e entender o mundo. Sobre o trabalho como princípio educativo,

[...] a afirmação remete à relação entre o trabalho e a educação, na qual se afirma o caráter formativo do trabalho e da educação como ação humanizadora por meio do desenvolvimento de todas as potencialidades do ser humano. Seu campo específico de discussão é o materialismo histórico em que se parte do trabalho como produtor dos meios de vida, tanto nos aspectos materiais como culturais, ou seja, do conhecimento, de criação material e simbólica, e de formas de sociabilidade (CIAVATTA, 2009, p. 408).

Consideradas na sua historicidade, as dimensões ontocriativas do trabalho são o fundamento mesmo das relações entre trabalho e educação. Na perspectiva do materialismo histórico, Trabalho e Educação ou Trabalho-Educação, ao contrário de um agrupamento de palavras, devem ser entendidas na sua dialeticidade, questão básica para a análise das dimensões ético-políticas e técnico-produtivas da organização do processo de trabalho e da formação/educação de trabalhadores. 
A organização do processo de trabalho diz respeito aos modos pelos quais em diferentes espaços/tempo históricos são criadas e recriadas as condições para garantir a produção da vida social, o que requer a transformação do mundo natural em coisas úteis para os seres humanos. A base material da produção, os critérios de divisão do trabalho e o estabelecimento de normas e regras de convivência têm como referência a cultura do trabalho partilhada pelos grupos humanos e determinada, em última instância, pela forma de propriedade dos meios de produção. A organização do processo de trabalho requer um conjunto de informações e conhecimentos originados do trabalho vivo e tecidos na própria atividade do trabalho, os quais vão se constituindo em métodos e técnicas engendradas e acumuladas ao longo da história da humanidade.

A (re)criação do mundo social só é possível graças à força de trabalho, ou seja, à capacidade humana de mobilizar as energias físicas, mentais, emocionais e morais que, a partir de uma base natural, são produzidas culturalmente pela experiência e pela educação, materializadas na corporeidade e no espírito do trabalhador. A organização do processo de trabalho pressupõe a coordenação não apenas do esforço individual, mas da força coletiva de trabalho, ou seja, do conjunto de faculdades físicas, intelectuais e emocionais existentes no corpo de cada um dos trabalhadores que, posto em movimento, pode produzir valores de uso de qualquer espécie (MARX, 1980). Como não poderia ser diferente, em toda e qualquer formação social, a educação de trabalhadores/as carrega consigo tanto dimensões técnico-produtivas como ético-políticas.

De certo modo, podemos dizer que, ao longo da história do capitalismo, as formas de organização do processo de trabalho acompanham, pelo menos, cinco grandes momentos do desenvolvimento das forças produtivas. Na manufatura, a organização do processo de trabalho quase não se distingue daquela encontrada no artesanato das corporações de ofício, a não ser pela reunião de um número maior de trabalhadores simultaneamente ocupados num mesmo local. No capítulo XI de $O$ Capital, que trata sobre Cooperação, Marx (1980, p. 370) explica que, na verdade, na manufatura "amplia-se apenas a oficina do mestre artesão". Nesse momento, a base técnica da produção ainda permite ao operário o controle do processo de trabalho; a produção de excedentes é o resultado do prolongamento da jornada de trabalho (mais- valia absoluta) - ao que Marx denomina de subsunção formal do trabalho ao capital.

Com a Revolução Industrial, iniciada na Inglaterra na metade do século XVIII, a maquinaria (movida a vapor e posteriormente pela energia do carvão e elétrica) passa a ser o elemento ativo na organização do processo de trabalho, possibilitando alterações na maneira pela qual se dá a criação de excedentes. O desenvolvimento tecnológico e com ele a divisão técnica do trabalho tornam-se a chave para garantir a intensificação do ritmo da produção e, por conseguinte, a subsunção real do trabalho ao capital.

No início do século XX, com o advento do taylorismo, a "gerência científica" encarrega-se da divisão pormenorizada das tarefas, da separação entre trabalho manual e intelectual de maneira a retirar da oficina todo e qualquer trabalho cerebral e centrar a ciência do trabalho no departamento de planejamento (BRAVERMAN, 1981). A Organização Racional do Trabalho, idealizada por Frederick Taylor (1979), requer, dentre outros, o estudo dos tempos e movimentos de maneira a permitir que o operário execute a tarefa de forma mais simples e rápida. Por sua vez, o estudo da fadiga humana, em voga na época, teve como objetivo evitar a exaustão do trabalhador e, consequentemente, a diminuição da produtividade do trabalho. Além de incentivos salariais e prêmios por produtividade, cabe à "gerência científica" buscar outros meios para alcançar um "dia ótimo de trabalho", driblando a "preguiça e vadiagem" e outras formas de resistência dos trabalhadores ao processo de valorização do capital. Com a Grande Depressão, em 1929, a 
Escola de Relações Humanas, de Elton Mayo, tratou de estudar as formas de disciplinamento e ajuste da subjetividade do trabalhador à sociabilidade requerida no processo de trabalho. Ao analisar a degradação do trabalho no século XX, Braverman (1981, p. 84) enfatiza que "o taylorismo domina o mundo da produção; os que praticam as 'relações humanas' e a 'psicologia industrial' são a turma de manutenção da maquinaria humana”.

Entre os anos de 1930 e 1970, o fordismo contribui para aperfeiçoar as premissas da "administração científica" de Taylor. Tendo seu ápice nas décadas de 1950 e 1960, período conhecido como "anos dourados" do capitalismo, a organização fordista do processo de trabalho caracteriza-se, entre outros aspectos, pela produção em série, em grande escala, massificada; pelo maquinário pesado, com automação rígida (trabalho padronizado); pela linha de montagem por meio de esteiras rolantes; e pela divisão pormenorizada das tarefas, que exige absorção de grande número de trabalhadores assalariados fixos. Merece destaque o fato de o regime fordista ser acompanhado pelo Estado do Bem-Estar Social que lhe deu sustentação para garantir o emprego em quantidade, salários compensadores e, por conseguinte, o consumo em massa. Para Antônio Gramsci, filósofo italiano, o fordismo não se constituiu apenas como um novo modo de produzir, mas também como uma nova cultura, um novo modo de vida (american way of life) que se estendeu a todas as esferas da vida social: "A hegemonia vem da fábrica e, para ser exercida só necessita de uma quantidade mínima de intermediários profissionais da política e da ideologia" (GRAMSCI, 1976, p. 381-382).

Para garantir a subsunção real do trabalho ao capital, é preciso distribuir as máquinas e equipamentos e estabelecer um plano para que os trabalhadores coletivos possam garantir o máximo de produtividade para o capital. Assim, no regime de acumulação flexível, quinto momento de desenvolvimento das forças produtivas do capital, que se inicia a partir da década de 1970, a organização do processo de trabalho apresenta características como: a) produção variada e em pequena escala, de acordo com as demandas específicas do mercado consumidor; b) automação flexível, com base nas tecnologias informacionais, o que permite que o trabalhador opere várias máquinas ao mesmo tempo; trabalho flexível/polivalente; c) trabalho realizado em equipe (e não individualmente, como no fordismo); d) número reduzido de trabalhadores fixos. Antunes (1999, p. 14) afirma que "enquanto na fábrica fordista aproximadamente $75 \%$ da produção era realizada no seu interior, a fábrica toyotista é responsável por somente $25 \%$ da produção, tendência que vem se intensificando ainda mais". Na organização toyotista, generalizada a partir da experiência da fábrica da Toyota, no Japão, na década de 1950, a flexibilização das relações entre capital e trabalho se dá pela terceirização ou subcontratação de empresas ou de mão de obra, o que reduz sobremaneira os custos da produção. Importante mencionar que o regime de acumulação flexível vem acompanhado pelas políticas neoliberais que retiram dos trabalhadores os direitos sociais que haviam sido garantidos pelo Estado do Bem-Estar Social

Em síntese, é possível afirmar que, em todas as suas fases, o desenvolvimento da base técnica (e ético-política) da produção capitalista tem estado, visceralmente, a serviço do projeto societário da burguesia: a valorização sobremaneira do capital. A rotina de trabalho está sob o comando do capitalista, uma vez que a propriedade dos meios de produção e a compra da força de trabalho lhe conferem tal "direito". Técnica e politicamente, os proprietários dos meios de produção da vida social têm criado e recriado formas de submeter homens e mulheres às regras, normas e a um modo de ser que, direta ou indiretamente, seja produtivo ao capital. Não por casualidade, Marx (1980, p. 484) assinala que "o látego do feitor de escravos se transforma no regulamento penal do supervisor". 
Contudo, nosso propósito é destacar que há outras formas de trabalho, entre elas as que ocorrem em espaços/tempos revolucionários, ou seja, em momentos históricos em que são produzidas mudanças estruturais na sociedade; o confronto entre capital e trabalho se manifesta por meio de revoltas e rebeliões, existindo a dualidade de poderes ou vitória da classe trabalhadora. Nesses espaços/tempos que, genericamente denominamos de "espaços/tempos do trabalho de produzir a vida associativamente" ${ }^{3}$, o que homens e mulheres vão produzir? Para quem vão produzir? Quais são as necessidades da comunidade local e do conjunto da sociedade? Os produtos e serviços serão destinados ao mercado? Qual mercado? Com que objetivo? Como se decide sobre "quem faz o quê" no processo de trabalho? A organização permite que todos os trabalhadores associados se apropriem do conteúdo do trabalho e definam os rumos da produção? Quais os critérios para distribuir os excedentes? Quem será beneficiado com o produto do trabalho?

Estamos nos referindo especificamente às experiências em que à classe trabalhadora cabe a "ciência da gestão" e/ou desvendar seus segredos. Nelas, os processos de educação dos sujeitos-trabalhadores requerem, entre outros, a mobilização e rearticulação de saberes produzidos no trabalho e em outras instâncias sociais, transformado os saberes produtivos para o capital em saberes socialmente produtivos (PUIGGRÓS; GAGLIANO, 2004) para o trabalho. Daí a necessidade de projetos educativos de cunho emancipatório, socialmente referenciados na reprodução ampliada da vida (e não do capital), que se coadunem na perspectiva de uma pedagogia da produção associada (TIRIBA, 2001), da pedagogia da autogestão e da autogestão da pedagogia (NASCIMENTO, 2011) e que se plasmem nos processos mais amplos de educação/formação em economia solidária (ADAMS, 2013). Esses projetos teriam como fundamentos teóricos as experiências de trabalho associado e, no sentido mais amplo, os diversos trabalhos necessários para produzir a vida associativamente.

Entendemos que o trabalho associado ou produção associada deve ser analisado enquanto totalidade social, considerando as determinações e mediações que tecem sua materialidade histórica. Mesmo atravessadas por mediações de segunda ordem do capital (MÉSZÁROS, 2006), as experiências de trabalho associado nos remetem

[...] às relações econômico-sociais e culturais em que os/as trabalhadores/as têm a propriedade e/ou posse coletiva dos meios de produção e cuja organização do trabalho (material e simbólico) é mediada e regulada por práticas que conferem aos sujeitos coletivos o poder de decisão sobre o processo de produzir a vida social. Diz respeito a um conjunto de práticas coletivas de pessoas ou grupos sociais que se identificam por compartilhar concepções de mundo e de sociedade fundadas no autogoverno e autodeterminação das lutas e experiências das classes trabalhadoras. Ao contrário da heterogestão, os princípios, as regras e normas de convivência que regem o trabalho associado e autogestionário são criados e recriados pelos seus integrantes (TIRIBA; FISCHER, 2012, p. 612).

Partimos do suposto de que, em especial para a classe trabalhadora, tem-se tornado crucial o desafio de articular pelo menos duas dimensões da formação humana, as quais se articulam. Isso pode ser evidenciado em momentos revolucionários, quando está em jogo a hegemonia do trabalho sobre o capital, e também quando, subsumidos no interior da sociedade capitalista, um grupo de trabalhadores ou uma comunidade inteira persistem em criar, recriar e afirmar uma cultura do trabalho que contrarie a perspectiva de mercantilização da força de trabalho e da própria vida. Indicamos que nesses contextos de 
trabalho, os saberes técnico-produtivos são mobilizados e recompostos em função de um determinado projeto societário, o que requer a relação dialética como os saberes éticopolíticos regidos pelos princípios econômico-filosóficos, políticos, sociais e culturais que fundamentam o processo de trabalho e o processo educativo.

\section{Memória, experiência do trabalho associado e educação}

Nos espaços/tempos históricos em que se materializam a produção associada/ trabalho associado e que, genericamente, podem ser denominados de espaços/tempos do trabalho de produzir a vida associativamente (FISCHER; TIRIBA, 2013), estão fortemente presentes as tensões entre formação ético-política e formação técnico-produtiva. É nos espaços/tempos revolucionários, objeto deste texto, onde se verifica a dualidade de poderes e onde os confrontos entre capital e trabalho se manifestam por meio de revoltas e rebeliões, entre outros. É o caso da Comuna de Paris (1871), dos Soviets, na Rússia (1905 e 1917), da Guerra Civil Espanhola (1936-1939), dos conselhos operários de Turim, na Itália (19191921), da Iugoslávia (1950) e do Chile (1972), da Revolução dos Cravos em Portugal (1974), entre tantos outros em que trabalhadores e trabalhadoras, com diferentes graus de controle dos meios de produção, viveram experiências de trabalho associado, entendidas como experiência de classe (THOMPSON, 1987). Nesse sentido, reiteramos que falar de experiências também exige pensar a sua natureza e o modo pelo qual são registradas, transmitidas e reelaboradas socialmente. Tendo em conta o princípio educativo do trabalho, destacar como os trabalhadores/as recompõem e dotam de significado as suas memórias individuais/coletivas (HALBWACHS, 2003), as quais se tornam suporte de apreensão de um dado processo histórico.

Vejamos, por exemplo, alguns registros das experiências de classe ocorridas durante a Guerra Civil Espanhola (1936-1939), particularmente na Asociación Colectiva de Trabajo Almacenes Quirós (ACTAQ), indústria de produtos têxteis, com cerca de 500 trabalhadores, localizada na cidade de Madrid, fundada no ano de 1893, a qual, durante a revolução popular, passou ao controle do Estado, sendo representado por um conselho formado por dez operários. Tendo em conta o contexto de luta contra o fascismo, em que a classe trabalhadora tomou para si os rumos da produção, vale apreender as concepções de sociedade, trabalho e educação que os trabalhadores associados tentavam imprimir na fábrica coletivizada (TIRIBA, 2006). Em seguida, enveredamos pelo Processo Revolucionário em Curso (PREC), ocorrido entre 1974 e 1975, período subsequente ao golpe militar de 25 de abril de 1974, que pôs fim a 48 anos de fascismo em Portugal (TIRIBA, 2010). Como fonte histórica, recorremos ao Jornal $O$ Combate, publicado entre 1974 e 1978, com o objetivo de divulgar as práticas políticas dos trabalhadores portugueses que ocuparam fábricas e criaram formas organizativas autônomas, instaurando o regime de autogestão. Para contemplar as práticas dos adeptos do controle operário, em contraposição aos autogestionários, elegemos como fonte regulamentos de comissões de trabalhadores, os quais nos informam sobre organização do processo de trabalho e os desafios educativos.

Em Almacenes Quirós, aqueles que, ao longo da história da empresa, haviam sido impedidos de criar e recriar plenamente seu trabalho, agora se colocavam diante da possibilidade de se transformar em governantes de si e de seu trabalho. Para tal, era preciso articular conhecimento prático e conhecimento científico e articular técnica e ciência conforme as necessidades político-sociais de seu projeto de classe. Nessa perspectiva, Reinoso, do Conselho Operário, escrevia aos demais companheiros: 
Diz Lenin: Toda cozinheira deve saber administrar o Estado [...] devemos aspirar, na sociedade futura, que cada cidadão, cada operário esteja capacitado a desempenhar esta função [...]. Isto é que nos ensina a frase de Lenin: A questão da capacitação de todos sem distinção de sexo nem de cargo na produção. Então, quando esta capacitação for um fato, sem diferenças a não ser os talentos naturais (que ao longo do processo também desaparecerão), então, o problema da responsabilidade dos postos de chefia se haverá simplificado. Com a compreensão entre o camarada responsável e seus colaboradores se fará mais fácil e mais eficaz a tarefa da produção. ${ }^{4}$

Contrariando a lógica da organização capitalista do trabalho, a perspectiva de formação de "técnicos" não era restrita aos membros do Conselho e sim um desafio ao conjunto dos operários. O projeto educativo era parte integrante do projeto de ser humano e de sociedade que a revolução popular começava a ensaiar. Cada um dos trabalhadores deveria deixar de ser um apêndice da máquina:

É preciso acabar com o operário autômato, sem iniciativa nem curiosidade por sua profissão. É necessário que o operário conheça a fundo suas máquinas para que esta conjugação de braço e ferramenta ajude a criar o amor do trabalhador por sua obra; ajude a instaurar uma nova moral do trabalho com obrigação social e, por último, contribua para que desapareça o odioso conceito de trabalho como castigo, que tanto influenciou para a desordem social que tivemos que suportar durante a era capitalista.

Creio que o trabalho em coletividade será a forma do trabalho no futuro, já que este será a base de uma colaboração conjunta e entusiasta, onde cada um dará de si todo o rendimento que seja capaz, sem escamoteações, sem regateio de esforços; pois sabe que suas atividades é recompensada com o engrandecimento e o bem estar da humanidade. ${ }^{5}$

O cotidiano vivido na Asociación Colectiva de Trabajo Almacenes Quirós representou uma escola de formação de trabalhadores, uma condição sine-qua-non do processo produtivo. A educação seria fundamentalmente técnico-política. Queriam superar a formação estreita, utilitarista e imediata para o mundo do trabalho e propiciar uma formação integral. O processo educativo dos novos dirigentes da produção deveria contemplar as diferentes instâncias do ato de conhecer, desde a máquina aos bancos escolares, passando pela vida artística e cultural. O ponto de chegada seria uma nova maneira de fazer e conceber o mundo do trabalho, contribuindo para que, no futuro, pudessem tornarse intelectuais de novo tipo, ou melhor, sujeitos produtores e criadores da história (GRAMSCI, 1982).

E, em Portugal, como já ressaltamos, onde a classe trabalhadora viveu entre 1974 e 1975 o Processo Revolucionário em Curso (PREC), imediatamente após a derrubada do fascismo, a população foi para as ruas, ocupou quartéis, escolas e fábricas; criou comissões de trabalhadores, moradores e soldados. O sistema capitalista foi posto em xeque. Ao analisar o regulamento das comissões de fábrica, é interessante observar as considerações sobre os saberes necessários para garantir a continuidade da produção e, com ela, os rumos da revolução. Nos registros abaixo, encontrados, por exemplo, no Caderno da Comissão de Trabalho da Plessey Automática, observa-se como nesse processo há elementos constitutivos do "fazer-se" da classe trabalhadora, as lutas sociais e políticas e os processos educativos vividos e percebidos no trabalho, que vão tecendo uma memória 
coletiva do trabalho. Entre os saberes do trabalho associado, necessários para colocar os meios de produção a serviço da classe trabalhadora, devem ser destacados:

[...] O conhecimento de terrenos, edifícios, propriedades, automóveis e participações financeiras noutras empresas e das relações da empresa com outros do mesmo grupo econômico, com vistas a definir o que foi adquirido pela empresa [...].

[...] O conhecimento da idade das máquinas, de forma a evitar que o equipamento obsoleto continue a funcionar, implicando aumento da produção, substituindo-o logo que possível por máquinas que correspondem à evolução Tecnológica e às necessidades da empresa. [...] A verificação da existência de matérias-primas de origem nacional que podem ser utilizadas para substituir matérias-primas até então importadas, e também a procura de outros mercados de substituição para não se depender de um pequeno grupo de países capitalistas.

[...] Verificação da organização da produção de forma a combater os tempos mortos, eliminar os desperdícios, compensar e aproveitá-los, bem como os gastos excessivos de energia e matérias-primas que, a conseguir, se melhorará a situação econômica da empresa.

[...] permitir um conhecimento mais amplo do processo produtivo, o que, não quer dizer deixar para trás o aperfeiçoamento Técnico e individual [...] O estudo da resolução dos passivos financeiros, a forma como era utilizada pelo capital para desviar a mais valia das empresas que não devem ser os trabalhadores a pagar as consequências que se podem traduzir no aumento dos preços.

[...] O estudo dos orçamentos que correspondem ao seu custo real, de forma a evitar a sabotagem. ${ }^{6}$

Também em Portugal, as operárias da fábrica Charminha carregam consigo os saberes da "escola da vida", bem como outros saberes adquiridos e produzidos em situações de trabalho assalariado e sob o regime de autogestão. Vislumbram a possibilidade de serem as "senhoras" do processo de trabalho, o que se evidencia no diálogo entre uma operária e um colaborador do jornal, na mesa-redonda publicada pelo $O$ Combate:

JORNAL O COMBATE - Portanto, agora não existe ninguém que propriamente esteja como chefe.

OPERÁRIA - Agora há duas pessoas, ou seja, três, mas uma está doente, que orientam o trabalho para as pessoas não andarem em pé e assim.

JORNAL O COMBATE - Portanto, para trabalhar, os chefes não são precisos para nada.

OPERÁRIA - Ah, pois, não precisamos de chefes, não senhor. ${ }^{7}$

Mesmo se utilizando de meios "rudimentares" de trabalho, "a base técnica da produção" torna-se "nova" à medida que ensaia uma maneira de produzir suas necessidades materiais e espirituais com base em novos parâmetros de convivência. Na organização do processo de trabalho, o novo está exatamente na qualidade das relações sociais de produção que são estabelecidas. Não por acaso, no comunicado publicado no Jornal $O$ Combate (n. 19, de 14 a 28 de março de 1975), os trabalhadores têxteis da SOUSABREU explicam, entre outras coisas:

Também aprendemos que os patrões não servem para nada e não ser para explorar e ficar com o produto do nosso trabalho. Hoje dentro da fábrica as coisas são diferentes. Todos trabalhamos para nós. Todos nos 
sentimos mais à vontade. Isto não quer dizer que não temos problemas. Mas se formos todos a resolver não há problema que não se resolva. Aprendemos que só a união faz a nossa força. Também aprendemos que a solidariedade não é uma palavra sem sentido para os operários ${ }^{8}$.

No texto introdutório à Mesa Redonda que promoveu o debate entre representantes de fábricas ocupadas em Portugal, o redator do Jornal $O$ Combate nos conta que os problemas comuns nas fábricas Ornitex, Sousabreu, Artedu e Eduardo Pereira Pinto são os seguintes:

- Divisão entre os trabalhadores: há sempre uma parte dos trabalhadores que preferiria indenizações, a continuar a trabalhar sem patrão; e um certo isolamento das comissões de trabalhadores.

- Dificuldades de fornecimento de matérias-primas e de escoamento dos produtos.

- O caso da Artedu apresenta ainda problemas mais graves, porque toda a sua maquinaria está em muito más condições e precisa de um certo investimento inicial para começar a funcionar. ${ }^{9}$

No periódico informativo da fábrica Almacenes Quirós, da Espanha, encontramos os seguintes registros sobre as dificuldades de produtividade do trabalho e sobre os desafios e dilemas dos processos educativos, respectivamente.

- O rendimento atual do trabalho pelo sistema Coletividade tem, até o momento, muita falta de compreensão por parte de alguns companheiros e companheiras que, devido às condições anteriores, ao se encontrarem agora com mais liberdade de trabalho, se sentem com mais direitos que antes, chegando, inclusive, a render menos, prejudicando com isto os interesses de nossa coletividade. ${ }^{10}$

[...] existem companheiros em nossa coletividade que ainda não solicitaram um só livro; pior ainda: que não conhecem a biblioteca [...]. A biblioteca já está aberta há 151 dias: neste tempo só foram utilizados 568 livros, dos quais, feita a divisão, encontramos 4 livros utilizados por dia. Atenção! Dos 300 companheiros que somos atualmente, somente quatro por dia solicitaram livros; com a particularidade de que estes quatro são quase sempre os mesmos. ${ }^{11}$

Importante considerar que Madrid, sede do Governo, centro político, comercial e financeiro do país, era a praça que mais interessava aos franquistas conquistar; era o local onde era mais difícil triunfar a revolução popular. Até 1939 , em dois anos e meio combatendo a sublevação franquista, o exército popular chegou a contar com 600 mil homens contra 500 mil nacionalistas em armas (incluindo-se as forças de Mussolini e Hitler). São estimadas cerca de 100 mil mortes nos campos de batalha, das quais 10 mil somente nas lutas de Madrid. Em setembro de 1937, um balanço das mercadorias produzidas em Almacenes Quirós indicava 75 mil blusas de lã, 210 mil camisas e 16 mil cuecas (VESTIDO, 15/09/37). As necessidades de reorganização da produção, impostas pela Guerra Civil, levaram os trabalhadores de Quirós ao extremo de suas capacidades físicas: 70 horas de trabalho semanal, elevando a fabricação de camisas e jérseis de lã, para suprir as necessidades das frentes e da retaguarda. De acordo com a voz de dois operários: 
Nossas fábricas estão produzindo, neste momento, o máximo que se pode pedir. Muitas companheiras (todos nós temos conhecimento) estão cumprindo uma jornada de sessenta a setenta horas semanais, o que significa uma média de dez a doze horas diárias, durante a qual produzem de 1.000 a 1.200 camisas diárias, números que, contando com a dificuldades do momento [...] ultrapassam em muito a todos os que atingimos até agora! ${ }^{12}$

Podemos inferir que, nas experiências espanhola e portuguesa, o trabalho e a formação técnico-produtiva e ético-política eram considerados dimensões fundamentais do projeto maior de sociedade, ainda que não necessariamente caminhassem na mesma direção. No entanto, fontes também nos mostram que se, por um lado, a prática educativa tinha como perspectiva a socialização da cultura e a formação, por outro, a Organização Racional do Trabalho, inspirada nos princípios stajanovista/taylorista, reproduzia a separação entre corpo e alma, entre pensar e fazer o mundo do trabalho. Em especial na Espanha, a educação no chão de fábrica contribuía, de alguma maneira, para promover o acesso aos fundamentos científico-tecnológicos; no entanto, determinada pelas condições objetivas da Guerra Civil, as práticas laborais pareciam manter um trabalho mecânico e repetitivo. Em síntese, a dicotomia projeto educativo e projeto laboral era a manifestação da falsa dicotomia, instituída pelo capital, entre o mundo da cultura e o mundo da produção e, em síntese, entre trabalho intelectual e trabalho manual. Ainda que "científica", a produção dos bens materiais era, em si, deseducadora/deformadora, ao contrariar a perspectiva de um trabalho que considerasse o ser humano em sua dimensão omnilateral.

Interessante é observar que, nas experiências analisadas, o "passado" não deixou de imperar sobre as experiências em curso, o que revela a persistência da hegemonia do modo de produção capitalista em relação à nova cultura econômica e do trabalho que os dirigentes das comissões de trabalhadores desejavam construir. Por se realizar no contexto de uma intensa luta de classes no conjunto da sociedade e no próprio chão de fábrica, o trabalho associado pode se desfigurar enquanto elemento de emancipação humana. Portanto, falar em recuperação da memória do trabalho construída a partir do princípio educativo do trabalho associado também requer pensar na problemática das bases (des)educativas do trabalho alienado e de outras determinações econômicas, políticas de culturais do capital.

Desse modo, evocar memórias coletivas que fomentem respostas mentais e sociais à construção de uma sociedade distinta e contraposta à sociedade produtora de mercadorias implica em luta, em conflitos pela memória, em um contexto ideológico forjado de símbolos, visões de mundo que constituem o "fazer-se" da classe trabalhadora. Implica em posicionamentos ideológicos, em uma construção parcial e comprometida com interesses implícitos na própria seletividade da memória social.

\section{A título de conclusão}

Neste texto, fazemos referências à experiências históricas de trabalho associado que, de modo contrário à perspectiva das relações capitalistas de produção da vida social, buscavam um novo sentido para o trabalho e a vida em sociedade. Destacamos a dialeticidade entre saberes técnico-produtivos e saberes ético-políticos regidos por princípios econômico-filosóficos, políticos, sociais e culturais que fundamentavam o projeto societário, o trabalho associado e o projeto educativo de formação de trabalhadores. Com isso, assinalamos importantes matrizes históricas do "fazer-se" da classe trabalhadora (THOMPSON, 1987). 
Aqui, não podemos nos aprofundar mais na riqueza da experiência do trabalho associado na Espanha (1936-1939) e no chamado Processo Revolucionário em Curso (PREC), em Portugal (1974-1975). Mesmo assim, é possível observar nos contextos históricos em que, ao contrário da perspectiva das relações capitalistas de produção da vida social, os trabalhadores/as apresentam-se como possíveis "senhores (as)" da organização do processo de trabalho, os saberes técnico-produtivos são mobilizados e recompostos em função de um determinado projeto societário, o que requer a relação dialética como os saberes ético-políticos, regidos pelos princípios econômico-filosóficos, políticos, sociais e culturais que fundamentam o trabalho associado e o próprio processo educativo. Considerando as particularidades e diferenças sócio-históricas em ambos os contextos de confrontação política comparecem experiências associativas que desempenham, ainda que contraditoriamente, um papel crucial na transformação de condições de opressão e exploração. Expectativas políticas, econômicas, culturais e educativas proporcionavam a mobilização, sistematização e produção de novos saberes e novas aprendizagens sobre a vida em sociedade, ensaiando culturas do trabalho de novo tipo. A pesquisa nos reafirma que a formação integral e omnilateral de trabalhadores/as (inclusive dos trabalhadores/educadores) é parte integrante do processo maior de fazer/pensar a realidade humana-social, de refletir sobre o ir e vir na vida real e na teoria, de inventar as formas pelas quais, ao longo da história, construímos e reconstruímos os mundos do trabalho.

De certo modo, poderíamos dizer que nos registros encontrados acerca do trabalho associado, em ambas as experiências, guardadas suas particularidades, os trabalhadores e as trabalhadoras recorrem a memórias individuais e coletivas de experiências comuns, de vivência da exploração do trabalho, próprio do modo de produção capitalista. Sabemos que se, por um lado, experiência de classe é determinada, em grande medida, pelas relações de produção em que os homens nasceram" (THOMPSON, 1987, p. 10), por outro, a consciência de classe não é um reflexo imediato dessas relações, mas resulta das formas "como essas experiências são tratadas culturalmente" (p. 10). Voltando a Maurice Halbwachs (2003), diríamos que daí decorrem quadros sociais de classe, que passam a ser recompostos e reconstruídos coletivamente com base nas necessidades de um projeto de transformação da realidade.

A partir desses e de outros pressupostos, poderíamos dizer que, ancorada num quadro social de exploração, a memória de classe é reelaborada frente a valores e visões de mundo apreendidos no processo da luta política. Consenso e luta por esses aprendizados estão presentes entre os registros das experiências mencionadas, considerando que há uma memória da sociedade hegemônica, que continua incorporada por dados trabalhadores/as. Mas há, sobretudo, a predominância daqueles que lutam pela transformação e põem a ordem política e normativa dessa sociedade em xeque, buscando a reconstrução seletiva do passado, por meio da recriação das relações históricas entre trabalho e educação.

Sublinhamos que nesses processos há uma memória coletiva sendo recriada na organização de um processo de trabalho que se encontra sob o controle dos próprios trabalhadores, ou seja, coletivos de trabalhadores que convivem, compartilham experiências de trabalho associado e suas dimensões educativas, transformando memórias coletivas em memórias dinâmicas capazes de colocar sob crivo as contradições entre trabalho e capital. Aqui, a memória comparece como um importante instrumento de compreensão da experiência como práxis e de transmissão histórica da luta de classes (MAGALHÃES, 2007).

De tal modo, os registros das experiências de trabalho associado não revelam apenas narrativas históricas de experiências vividas no passado, mas também a reconstrução de visões de mundo que demonstram a densidade das formas de organização do processo de 
trabalho e de formação de trabalhadores/as como seres históricos, em um contexto social explicitamente valorado por uma concepção de classe.

É importante ressaltar que a rigor, do ponto de vista da mobilização das capacidades físicas, emocionais e intelectuais da força de trabalho e das condições objetivas e subjetivas que põem em ação o corpo do trabalhador, o trabalho em si pode ser considerado educativo, potencializador do desenvolvimento das faculdades humanas. No entanto, sob relações de dominação e opressão, o trabalho desconfigura-se como atividade ontocriativa. Ao retirar a propriedade dos meios de produção e com a possibilidade de definir a forma de organização do trabalho, o capitalismo desapropria a classe trabalhadora do processo, do produto e do saber sobre o trabalho e, por conseguinte, contribui para a desqualificação do trabalhador, forjando uma memória do trabalho enraizada na lógica do capital. Não por acaso vale a pena recuperar memórias do trabalho que considerem não apenas as relações capitalistas de produção, mas o conjunto das relações de produção necessárias para a reprodução ampliada da vida, entre elas as experiências históricas de trabalho associado consideradas como experiências de classe.

Para finalizar, nunca é demais dizer que essas e outras experiências de classe nos indicam a necessidade de, permanentemente, confrontar realidade e utopia. Como não poderia ser diferente, a formação integral de trabalhadores (inclusive dos trabalhadores/educadores) é parte integrante do processo de fazer/pensar a realidade humano-social, de refletir sobre ir e vir na vida real e na teoria, de inventariar as formas pelas quais, ao longo da história, construímos e reconstruímos o(s) mundo(s) do trabalho.

\section{Referências}

ANTUNES, Ricardo. Os sentidos do trabalho. São Paulo: Boitempo, 1999.

ADAMS, Telmo. Educação Popular e o Centro de Formação em Economia Solidária. $36^{a}$ Reunião Nacional da ANPED, GT 06, 2013. Disponível em: <http://www.anped.org.br>. Acesso em: 02 fev. 2016.

BRAVERMAN, Harry. Trabalho e capital monopolista: a degradação do trabalho no século XX. Rio de Janeiro: Zahar, 1981.

CADERNO DO PROGRAMA E CONTROLO OPERÁRIO. Comissão de Trabalhadores da Plessy Automática, 1974.

CIAVATTA, Maria. Trabalho como princípio educativo. In: PEREIRA, Isabel Brasil; LIMA, Julio César França. (Org.). Dicionário da Educação Profissional em Saúde. Rio de Janeiro: Escola Politécnica de Saúde Joaquim Venâncio, 2009. p. 408-415.

FISCHER, Maria Clara Bueno; TIRIBA, Lia. Saberes do trabalho associado. In: CATTANI, Antonio David et al. Dicionário internacional da outra economia. Coimbra: Almedina SA; São Paulo: Almedina do Brasil, 2009. p. 293-298. (Série Políticas Sociais).

FISCHER, Maria Clara Bueno; TIRIBA, Lia. Aprender e ensinar à autogestão: espaços/tempos do trabalho de produzir a vida associativamente. Perspectiva, Florianópolis, v. 31, n. 2, p. 527551, maio/ago. 2013.

GRAMSCI, Antônio. Americanismo e fordismo. In: GRASMCI, A. Maquiavel, a política e o estado moderno. Rio de Janeiro: Civilização Brasileira, 1976. p. 375-413. 
GRAMSCI, Antônio. Os intelectuais e a organização da cultura. Rio de Janeiro: Civilização Brasileira, 1982.

HALBWACHS, Maurice. A memória coletiva. Tradução de Beatriz Sidou. São Paulo: Centauro, 2003.

JORNAL O COMBATE, Portugal, n. 23, 16 a 30 de maio de 1975.

LAVABRE, Marie-Claire. Maurice Halbwachs y la sociología de la memoria. Revista Raison Présente, n. 128, p. 47-56, oct. 1998.

LAVILLE, Jean-Louis; GAIGER, Luiz Inácio; HESPANHA, Pedro. Dicionário Internacional da Outra Economia. São Paulo/Coimbra: Almedina Brasil Ltda; Edições Almedina S. A. 2009, p. 293-298.

MAGALHÃES, Lívia Diana Rocha. Educação, História e Memória: uma aproximação do estudo geracional. Revista HISTEDBR On-line, Campinas, n. 28, jun./jul. 2007.

MAGALHÃES, Lívia Diana Rocha. História, Memória e Geração: remissão inicial a uma discussão político-educacional. In: Revista HISTEDBR On-line, Campinas: FE-UNICAMP, n. 55, p. 94-103, mar. 2014.

MARX, Karl. O capital. Crítica da economia política. Rio de Janeiro: Civilização Brasileira, 1980. Livro 1, v. 1.

MÉSZÁROS, István. Para além do capital. São Paulo: Boitempo, 2006.

NASCIMENTO, Claudio. Momentos e ideias decisivos para uma história da autogestão. In: NASCIMENTO, Claudio. Autogestão da pedagogia. São Paulo: IIEP, 2011.

PRODUCCIÓN. Madrid: Órgano de Asociación Colectiva de Trabajo Almacenes Quirós, n. 2, 5 feb. 1937; n. 9, 20 mayo 1937; n. 12, 20 ago. 1937.

PUIGGRÓS, A.; GAGLIANO, R. (Dir.). La fábrica del conocimiento: saberes socialmente productivos en América Latina. Rosario: Homosapiens, 2004.

SAVIANI, Dermeval. Breves considerações sobre fontes para a História da Educação. In:

Revista HISTEDBR On-line, Campinas: FE-UNICAMP, n. especial, p. 28-35, ago. 2006.

TAYLOR, Frederick. Princípios da administração científica. São Paulo: Atlas, 1979.

THOMPSON, Edward P. A formação da classe operária inglesa. Tradução de Denise Bottman. Rio de Janeiro: Paz e Terra, 1987, v. 1.

THOMPSON, Edward P. Algumas observações sobre classe e "falsa consciência". In: NEGRO, A. L.; SILVA, S. (Org.). As peculiaridades dos ingleses e outros artigos. Campinas: Ed. da Unicamp, 2001. p. 269-281.

THOMPSON, Edward P. A miséria da Teoria. Rio de Janeiro: Zahar, 1981. 
TIRIBA, Lia. Economia popular e cultura do trabalho. Pedagogia(s) da produção associada. Ijuí: Unijuí, 2001.

TIRIBA, Lia. Processo de trabalho e processo educativo: notas sobre o "período de ouro" da educação de adultos em Portugal. Revista HISTEDBR On-line, Campinas: FE-UNICAMP, v. 39, p. 104-118, 2010.

TIRIBA, Lia. Trabalho e educação na guerra civil espanhola: cenas madrileñas sobre conselhos operários e coletivização da produção. Revista HISTEDBR On-line, Campinas: FE-UNICAMP, v. 21, p. 180-200, 2006.

TIRIBA, Lia; FISCHER, Maria Clara Bueno. Produção associada e autogestão. In: CALDART, Roseli Salete et al. (Org.). Dicionário da educação do campo. Rio de Janeiro: Escola Politécnica de Saúde Joaquim Venâncio; São Paulo: Expressão Popular, 2012. p. 612-618.

VESTIDO. Madrid: Unión General de los Trabajadores (UGT). Madrid, 15 set. 1937; (Portavoz del Sindicato de Trabajadores de la Industria del Vestido).

\footnotetext{
${ }^{1}$ Professora do Programa de Pós-Graduação em Educação da Universidade Federal Fluminense (UFF). Doutora em Ciência Política e Sociologia pela Universidade Complutense de Madrid. Membro do Núcleo de Estudos, Documentação e Dados sobre Trabalho e Educação - Neddate (UFF). liatiriba @ gmail.com

${ }^{2}$ Professora Plena do DFCH-UESB. Doutora em Educação pela UNICAMP. Coordenadora do Programa de Pós-Graduação em Memórias: Linguagem e Sociedade. Coordenadora Geral do Museu Pedagógico da UESB. lrochamagalhaes@gmail.com

3 Indicamos a existência de, pelo menos, mais dois "espaços/tempos do trabalho de produzir a vida associativamente": a) espaços/tempos da atual crise do capital e do trabalho assalariado, nos quais as estratégias associativas de trabalho e de sobrevivência se configuram como parte integrante da economia popular, economia popular solidária ou qualquer outra denominação que, embora não sejam sinônimos, anunciam a construção de uma economia distinta da racionalidade econômica capitalista e ; b) espaços/ tempos das culturas milenares dos povos e comunidades e tradicionais - são povos da floresta, comunidades indígenas, quilombolas, caiçaras, ribeirinhos e outros povos e comunidades tradicionais milenares situadas na Ásia, na África e nas Américas (México, Peru, Bolívia, Equador, por exemplo) (FISCHER; TIRIBA, 2013).

${ }^{4}$ PRODUCCIÓN, 05/02/37 - por Reinoso - Conselho Operário.

${ }^{5}$ Idem, 20/08/37 - por José Mantero - responsável pela Tricotagem.

${ }^{6}$ Caderno do Programa e Controlo Operário, Comissão de Trabalhadores da Plessy Automática.

${ }^{7}$ Jornal O Combate, Portugal, n. 7, de 27 de setembro a 03 de outubro de 1974.

${ }^{8}$ Idem, Portugal, n. 19, de 14 a 28 de março de 1975.

${ }^{9}$ Ibidem, n. 23, 16 a 30 de maio de 1975.

${ }^{10}$ PRODUCCIÓN, por Carlos Martins, 20/08/37.

${ }^{11}$ Idem, 15/09/37.

12 Ibidem, 20/05/37.
}

Recebido: Fevereiro/2017.

Aprovado: Abril/2017. 